\title{
Effect of protease inhibitors (indinavir and ritonavir) on the pharmacokinetics of gliclazide in rabbits
}

This article was published in the following Dove Press journal:

Research and Reports in Endocrine Disorders

18 January 2011

Number of times this article has been viewed

\author{
Kilari Eswar Kumar ${ }^{1}$ \\ Shaik Mastan ${ }^{2,3}$ \\ 'Pharmacology Division, University \\ College of Pharmaceutical Sciences, \\ Andhra University, Visakhapatnam, \\ Andhra Pradesh, India; ${ }^{2}$ Research and \\ Development Cell, Jawaharlal Nehru \\ Technological University, Hyderabad, \\ Andhra Pradesh, India; ${ }^{3}$ Cytel \\ Statistical Software and Services \\ Pvt Ltd, Pune, Maharashtra, India
}

\begin{abstract}
The objective of this study was to investigate the effect of protease inhibitors (indinavir and ritonavir) on the pharmacokinetics of gliclazide in rabbits and to evaluate the mechanism of interaction of the combination. Studies in rabbits were conducted with oral doses of gliclazide, selected protease inhibitor, and their combination with a 1-week washout period between each treatment (single dose followed by multiple dose treatment). Blood samples were collected at regular time intervals by marginal ear vein puncture and serum gliclazide levels were analyzed by high-pressure liquid chromatography. Pharmacokinetic analysis was performed by noncompartmental analysis using WinNonlin Software. In combination, ritonavir significantly increased serum gliclazide levels and altered the pharmacokinetic parameters of gliclazide in rabbits while indinavir had no significant effect. The percentage increase of serum gliclazide level was $22.34 \%$ and $27.78 \%$ following single-dose and multiple-dose treatment of ritonavir, respectively. The interaction of ritonavir with gliclazide is pharmacokinetic at a metabolic level (by CYP3A4 inhibition) in normal rabbits, while the interaction of indinavir with gliclazide is pharmacodynamic, which needs dose adjustment, and care should be taken when these combinations are prescribed for their clinical benefit in diabetic patients.
\end{abstract}

Keywords: gliclazide, indinavir, ritonavir, diabetes, HIV infection, pharmacokinetics

\section{Introduction}

Diabetes mellitus and HIV infection are major current health concerns worldwide, which need chronic and rational therapy. There is a strong relationship between HIV infection therapy and diabetes, especially with protease inhibitors (PIs). ${ }^{1}$ Insulin resistance, impaired glucose tolerance, and type 2 diabetes are conditions that are increasingly described in HIV-1-infected subjects receiving antiretroviral therapy. ${ }^{2}$ Among the many metabolic perturbations that occur as a result of HIV infection and its treatment, alterations in normal glucose-insulin homeostasis remain a particularly prevalent and alarming clinical change in affected patients. ${ }^{3}$ Much of the concern is due to the recognition of the long-term complications of insulin resistance and hyperglycemia in the context of the growing worldwide epidemic of type 2 diabetes mellitus. ${ }^{4}$ In this context there will be more chances of co-administration of antiretroviral drugs with oral hypoglycemic drugs in diabetes patients suffering with HIV infection which may lead to drug-drug interactions.

Drug interactions may occur when two drugs are concurrently administered and one drug (or both) may influence the time course of the other in the body. Drug interaction studies assume much importance especially for drugs that have a narrow margin of
Correspondence: Shaik Mastan Senior Pharmacokineticist, Cytel Statistical Software and Services Pvt Ltd (Subsidiary of Cytel Inc., USA), 8th Floor, Siddharth Towers, Kothrud, Pune-4I I029, Maharashtra, India Tel +9I-982208I869; +9I-9985I76604 Email shkmastan@gmail.com 
safety and where the drugs are used for prolonged periods of time. Diabetes mellitus is one such metabolic disorder that needs treatment for prolonged periods. Maintenance of normal blood glucose level is very important in this condition, since both hyperglycemia and hypoglycemia are undesirable. ${ }^{5}$ However, there is little information that describes the mechanisms of drug interactions of PIs with oral hypoglycemic drugs, information that is needed to provide rational therapy.

Oral hypoglycemic agents are used in the treatment of type 2 diabetes, among which gliclazide, a second-generation sulfonylurea derivative, is preferred in therapy because of its selective inhibitory activity towards pancreatic $\mathrm{K}^{+}$adenosine triphosphate (ATP) channels, antioxidant properties, low incidence of severe hypoglycemia, and other hemobiological effects. ${ }^{67}$ Indinavir and ritonavir are widely used PIs to treat HIV-infected patients.

We have previously studied the effect of indinavir and ritonavir on the pharmacodynamics (glucose, insulin, insulin resistance, $\beta$-cell function) of gliclazide in rats (normal and diabetic) and rabbits in terms of safety and effectiveness of the combination. ${ }^{8-10}$ These studies showed that both indinavir and ritonavir alone have a tendency to produce hyperglycemia and alterations in insulin-glucose homeostasis, and accelerated the diabetic condition in animal models. In combination, indinavir significantly reduced the effect of gliclazide while ritonavir increased the effect of gliclazide (contrary to its individual potency to exacerbate diabetes) and confirmed the existence of significant interactions. But the pharmacodynamic or pharmacokinetic mechanism of these interactions in nature is not known. Therefore the present study was investigated the effect of indinavir and ritonavir on the pharmacokinetics of gliclazide in rabbits and evaluated the mechanism of the interaction of the combination.

\section{Materials and methods Drugs and chemicals}

Gliclazide, PIs, and nicorandil are the gift samples from Micro Labs (Bangalore, India), Aurobindo Pharma Ltd (Hyderabad, India), and Sun Pharmaceuticals Industries Ltd (Ahmedabad, India), respectively. Acetonitrile (HPLC grade), orthophosphoric acid (AR grade), and dichloromethane (AR grade) were obtained from Qualigens Chemicals (Mumbai, India), SD Fine Chemicals (Mumbai, India), and Loba Chemie Pvt Ltd. (Mumbai, India), respectively. All other reagents or chemicals used were of analytical grade.

\section{Animals}

Normal albino rabbits of either sex of 3 months of age, weighing $1.25-1.75 \mathrm{~kg}$ were procured from the National Institute of Nutrition, Hyderabad, India. They were maintained under standard laboratory conditions at an ambient temperature of $25 \pm 2{ }^{\circ} \mathrm{C}$ and $50 \% \pm 15 \%$ relative humidity with a 12/12 light/dark cycle. Animals were fed with a commercial pellet diet (Rayan's Biotechnologies Pvt Ltd. Hyderabad, India) and water ad libitum. They were fasted for 18 hours prior to the experiment and during the experiment food and water were withdrawn as described in Drug administration section. The animal experiments were performed after prior approval of the study protocol by the Institutional Animal Ethics Committee. The study was conducted in accordance with the guidelines provided by Committee for the Purpose of Control and Supervision of Experiments on Animals (CPCSEA).

\section{Drug administration and blood samples collection}

In clinical practice, PIs and gliclazide in therapeutic dose are administered orally as antiretroviral and antidiabetic therapy, respectively. Hence, human therapeutic doses were extrapolated to rabbit based on body surface area ${ }^{11}$ and administered orally. Indinavir ( $56 \mathrm{mg} / 1.5 \mathrm{~kg}$ body weight) and ritonavir (14 mg/1.5 kg body weight) were suspended in 3\% CMC-Na for oral administration. ${ }^{8,9}$ Gliclazide (5.6 $\mathrm{mg} / 1.5 \mathrm{~kg}$ body weight) solution was prepared by dissolving it in a few drops of $0.1 \mathrm{~N} \mathrm{NaOH}$ then made up to the volume with distilled water. ${ }^{10}$

Two groups of 6 rabbits each were administered with $5.6 \mathrm{mg} / 1.5 \mathrm{~kg}$ body weight of gliclazide orally. The same group was administered with interacting drug (indinavir or ritonavir) and the combination of PI and gliclazide. A 1-week washout period was maintained between treatments. After this single dose interaction study the same group was continued for multiple-dose treatment with the daily treatment of interacting drug (indinavir or ritonavir) for the next 8 days with regular feeding. Later, after 18 hours fasting, they were again given the combined treatment on the ninth day. Blood samples were withdrawn from the marginal ear vein of each rabbit at $0,1,2,3,4,6,8,12,16,20$, and 24 hours. The blood samples collected from the rabbits were centrifuged at $3000 \mathrm{rpm}$ for 15 minutes for obtaining the serum for analysis.

\section{Chromatography}

A gradient high pressure liquid chromatograph (Shimadzu HPLC Class VP series) with two LC-10AT VP pumps, 
variable wavelength programmable UV/VIS detector SPD-10A VP, CTO-10AS VP column oven (Shimadzu), SCL-10A VP system controller (Shimadzu), and RP C-18 column $(250 \mathrm{~mm} \times 4.6 \mathrm{~mm}$ I.D.; particle size $5 \mu \mathrm{m}$; YMC Inc., USA) was used. The HPLC system was equipped with the software Class-VP series version 6.12 SP2 (Shimadzu). The mobile phase consisted of acetonitrile and triple distilled water. The mobile phase components were filtered before use through a $0.22-\mu \mathrm{m}$ membrane filter and pumped in the ratio of 30:70 (acetonitrile:triple distilled water containing 0.5\% triethylamine) from the respective solvent reservoirs. The $\mathrm{pH}$ of the mobile phase was adjusted to 3.5 using orthophosphoric acid and column temperature was maintained at $30^{\circ} \mathrm{C}$. The mobile phase was eluted at a flow rate $0.8 \mathrm{~mL} / \mathrm{min}$ and the effluent was monitored at a wavelength of $230 \mathrm{~nm}$. The ratio of peak area of gliclazide to that of internal standard was used for the quantification of gliclazide in serum samples.

\section{Standard solutions}

Primary stock solution of $1 \mathrm{mg} / \mathrm{mL}$ of gliclazide and nicorandil (internal standard) were prepared in methanol and stored at $4^{\circ} \mathrm{C}$. Appropriate dilutions of gliclazide were made in mobile phase to produce concentrations of $10,1 \mu \mathrm{g} / \mathrm{mL}$ and 500, 200, 100, 50, and $20 \mathrm{ng} / \mathrm{mL}$. These dilutions were used to spike serum in the preparation of calibration curves. The internal standard working stock solution $(10 \mu \mathrm{g} / \mathrm{mL})$ was made from primary stock solution using mobile phase for dilution. Calibration samples were prepared by spiking $200 \mu \mathrm{L}$ of individual blank serum with an appropriate amount of drug on the day of analysis. Samples for the determination of recovery, precision, and accuracy were prepared by spiking control rabbit serum in bulk of appropriate concentrations $(20,100,500$, and $1000 \mathrm{ng} / \mathrm{mL})$ and stored at $-4^{\circ} \mathrm{C}$.

\section{Extraction from the serum}

To $200 \mu \mathrm{L}$ of serum, $100 \mu \mathrm{L}$ of nicorandil working solution and $0.1 \mathrm{~mL}$ of $0.07 \mathrm{M}$ phosphate buffer ( $\mathrm{pH} 4.5$ ) were added. After vortex mixing for 10 seconds, $4 \mathrm{~mL}$ of dichloromethane was added and the mixture was shaken vigorously for 1 minute. The mixture was then centrifuged for 5 minutes at $8000 \mathrm{rpm}$. A $3 \mathrm{~mL}$ aliquot of the upper organic layer containing gliclazide and internal standard was transferred to a clean test tube and evaporated to dryness at $50^{\circ} \mathrm{C}$. The residue was reconstituted into $100 \mu \mathrm{L}$ of mobile phase and a $25 \mu \mathrm{L}$ aliquot was injected onto the HPLC column. The eluent was detected at $230 \mathrm{~nm}$ by UV detector, and the data were acquired, stored, and analyzed by software Class-VP series version 6.12 SP2 (Shimadzu). Quantification was achieved by measuring the peak area ratio of the drug against the internal standard. The HPLC method was validated in terms of reproducibility, system suitability, recovery, accuracy, and precision and then applied for the estimation of gliclazide in rabbit serum.

\section{Pharmacokinetic analysis}

The peak concentration in plasma $\left(\mathrm{C}_{\max }\right)$ and concentration peak time $\left(\mathrm{T}_{\max }\right)$ were directly read from the concentrationtime data. Other pharmacokinetic parameters were determined on subjecting the concentration-time data to noncompartmental analysis using WinNonlin (version 5.0.1; Pharsight, Sunnyvale, CA) software. The elimination rate constant $\left(\mathrm{K}_{\mathrm{el}}\right)$ was determined by linear regression analysis of the log-linear part of the plasma drug concentration-time curve. A minimum of 3 data points was used to calculate the terminal half-life $\left(\mathrm{T}_{1 / 2}=\ln 2 / \mathrm{K}_{\mathrm{el}}\right)$. Area under the concentration-time curve (AUC) was calculated by use of the linear trapezoidal rule with extrapolation to infinity by dividing the last measured concentration by $\mathrm{K}_{\mathrm{el}}$. The mean residence time (MRT) was calculated using the formula $\mathrm{MRT}=\mathrm{AUMC}_{0 \text {-Inf }} / \mathrm{AUC}_{0 \text {-Inf }}$

\section{Statistical analysis}

Data were expressed as mean \pm SEM. Student's paired $t$-test was performed to test the effect of PIs on the pharmacokinetics of gliclazide, and $P<0.05$ was considered to be significant.

\section{Results \\ Chromatography}

The extraction procedure and the chromatographic conditions yielded a clear chromatogram for gliclazide. Recoveries of gliclazide from the spiked plasma samples (QC samples) estimated at 20,100, 500, and $1000 \mathrm{ng} / \mathrm{mL}$ concentrations, ranged from $97 \%$ to $99 \%$, and the limit of quantification is $20 \mathrm{ng} / \mathrm{mL}$. The intra-day precision of the assay was determined by analyzing 3 spiked serum samples at each concentration on the same day. For the determination of inter-day precision, the samples were analyzed on 4 different days. The intra-day \%accuracy (\%CV) for $20,100,500$, and $1000 \mathrm{ng} / \mathrm{mL}$ of gliclazide was 100.20 (0.20), 99.92 (1.72), 99.25 (1.25), and 99.29 (1.26), respectively. The inter-day \%accuracy ( $\% \mathrm{CV}$ ) for 20,100 , 500 , and $1000 \mathrm{ng} / \mathrm{mL}$ of gliclazide was $100.55(0.15), 99.86$ (1.32), 99.25 (1.20), and 98.92 (1.28), respectively. The 
system suitability parameters of gliclazide were determined as Limit of quantification $(\mathrm{ng} / \mathrm{mL}) 20$, theoretical plates 12248 , tailing factor 1.14 , retention time of gliclazide 7.82-8.32 minutes, retention time of internal standard (IS) 6.02-6.44 minutes, and resolution between drug peak and IS peak 2.316. The calibration curve (Figure 1) in the rabbit serum for gliclazide was linear within a concentration range of 20-1000 $\mathrm{ng} / \mathrm{mL}$, and the calibration regression equation was $y=m x+c$, where $y$ represents the peak area ratio of gliclazide to internal standard, $x$ represents the concentration of gliclazide, $\mathrm{m}$ is slope of the curve, and $\mathrm{c}$ is the intercept. The typical regression equation was $\mathrm{y}=0.0059 \mathrm{x}-0.0167$; $\left(r^{2}=0.9987\right)$. The typical chromatogram of gliclazide and internal standard is show in Figure 2.

\section{Pharmacokinetics}

The mean concentration versus time curves after oral administration of gliclazide in presence of indinavir and ritonavir are shown in Figures 3 and 4, respectively. The pharmacokinetic parameters of gliclazide alone, and in the presence of indinavir and ritonavir following single- and multiple-dose treatment in rabbits, are shown in Tables 1 and 2 , respectively. The serum gliclazide levels as well as pharmacokinetic parameters were not significantly altered following single- and multiple-dose administration of indinavir. The serum gliclazide levels were increased and pharmacokinetic parameters of gliclazide such as $\mathrm{C}_{\text {max }}, \mathrm{AUC}$, AUMC, $\mathrm{K}_{\mathrm{el}}$, and clearance were altered significantly following single- and multiple-dose treatments of ritonavir. The percentage increase in serum gliclazide level was $22.34 \%$ and $27.78 \%$ following single- and multiple-dose administration of ritonavir, respectively.

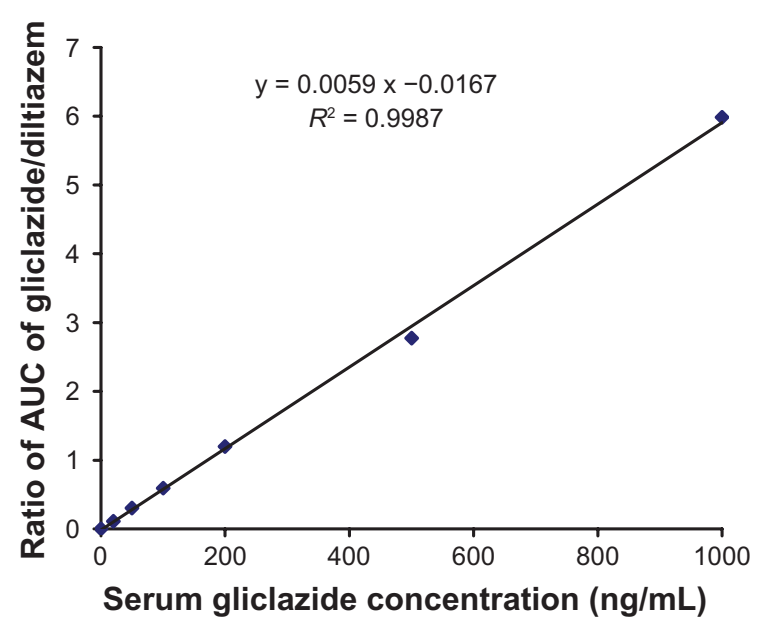

Figure I Standard graph for the estimation of gliclazide levels in rabbit serum.

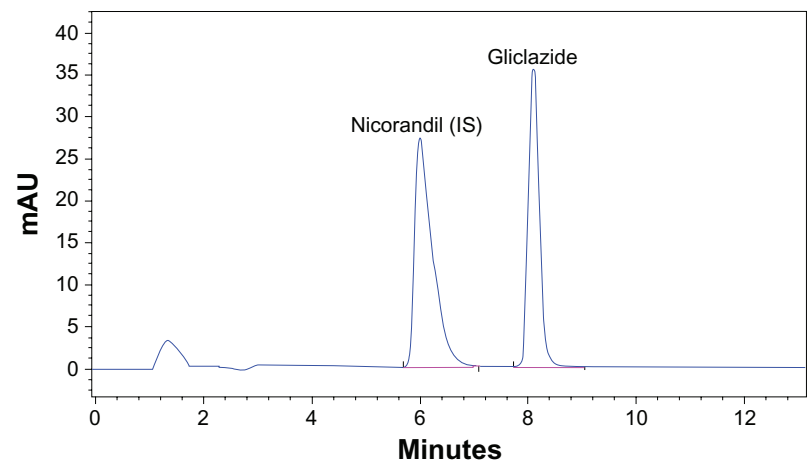

Figure 2 The typical HPLC chromatogram of gliclazide and internal standard (IS).

\section{Discussion}

HIV-infected patients are likely to suffer from diabetes mellitus ${ }^{12}$ and hence most often antiretroviral drugs are coadministered along with oral antidiabetes drugs. HIV-infection and diabetes are both chronic diseases that significantly affect lifestyle. When they intersect, the treatment regimens required for both diseases can be overwhelming for patients. Drug interactions are usually seen in clinical practice and the pharmacokinetic interactions are usually evaluated in animal models. ${ }^{13}$ Although animal models can never replace the need for comprehensive studies in human subjects, their use can provide important insights to help understand and evaluate the mechanism of potent interactions between drugs. Although scientists are continually searching for an animal species in which all of the pharmacokinetics of drugs is consistently the same as in humans, it is very unlikely that such an animal species will ever be found. ${ }^{14}$

Cytochromes P450 are a superfamily of hemoproteins that play a central role in the metabolism of endogenous compounds and xenobiotics. Cytochrome P4503A isoforms (especially

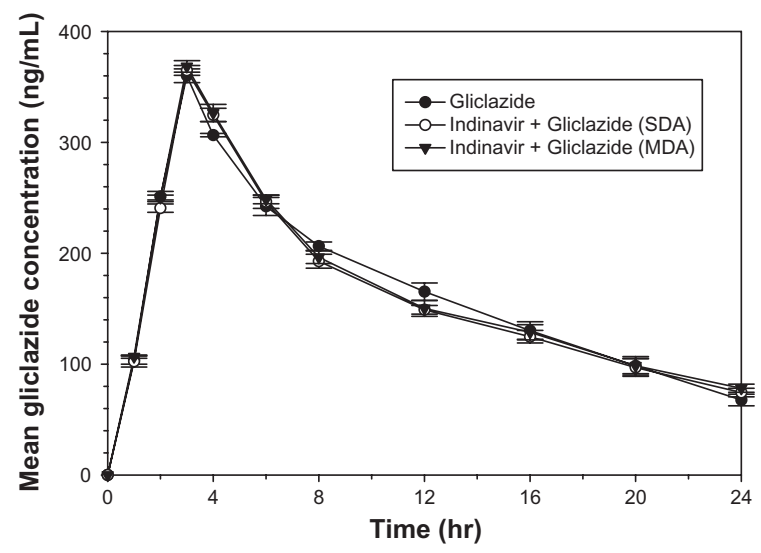

Figure 3 Mean serum gliclazide concentration $(\mathrm{ng} / \mathrm{mL})$ before and after treatment with indinavir in normal rabbits (mean $\pm S D, n=6$ ).

Abbreviations: SDA, single dose administration; MDA, multiple dose administration. 


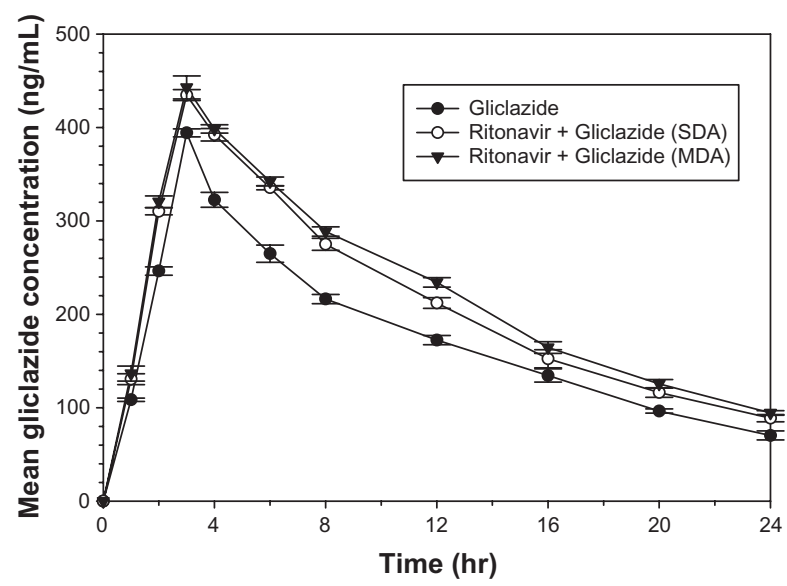

Figure 4 Mean serum gliclazide concentration $(\mathrm{ng} / \mathrm{mL})$ before and after treatment with ritonavir in normal rabbits (mean $\pm S D, n=6$ ).

Abbreviations: SDA, single-dose administration; MDA, multiple-dose administration.

CYP3A4) are the most abundant human isoforms that metabolize over one-half of clinically used drugs. ${ }^{15}$ However, it is well known that the metabolism of drugs may differ significantly among species, both qualitatively and quantitatively. ${ }^{16}$ Nevertheless, with a careful selection of animal species and appropriate experimental conditions, it is possible to make a reasonably good prediction of the pharmacokinetics of drugs in humans. It is worth noting that several findings have confirmed the functional similarity of CYP3A forms in rabbits and humans, suggesting that the rabbit is a valuable in vivo model for the assessment of drug interaction occurring at the first pass of drugs ingested. ${ }^{5,13,17-21}$ Moreover, studies performed on rabbits, evaluating the pharmacokinetics of other drugs metabolized in humans via CYP3A4 pathway ${ }^{22-24}$ have confirmed the usefulness of the rabbit model for such investigations. Based on these findings, and apart from convenience of serial blood sampling, we preferred rabbit as an animal model to perform the pharmacokinetic interaction studies. The multiple-dose effect of indinavir and ritonavir on the pharmacokinetics of gliclazide in rabbits was also studied since both are used for long-term treatment.

Gliclazide is known to produce hypoglycemic/antihyperglycemic activity by pancreatic ${ }^{25}$ (stimulating insulin secretion by blocking $\mathrm{K}^{+}$channels in the pancreatic $\beta$ cells) and extra pancreatic ${ }^{26}$ (increasing tissue uptake of glucose) mechanisms. Gliclazide is rapidly absorbed in all species (man, monkey, beagle, rabbit, and rat) with similar excretion in all species and inter-species variation in half-life. ${ }^{5,27}$ Our results in rabbits showed that gliclazide produced peak concentration at 3 hours with no second peak, while in rat models $^{5,8-10,20,21}$ and humans ${ }^{28}$ a second peak is reported to be common due to the presence biliary excretion and enterohepatic cycling of gliclazide. According to Davis et $\mathrm{al}^{29}$ the extent of mean enterohepatic recirculation observed in humans was consistent with animal data. This consistency addresses the probable correlation of preclinical animal studies with studies on human subjects, and their use might provide important insights into the mechanisms of drug interactions which would improve their understanding and provide the basis for rational therapy. Thus our results indicating gliclazide peak concentration at 3 hours and absence of biliary excretion and enterohepatic cycling in rabbits are consistent with our former pharmacodynamic studies ${ }^{8-10}$ as well as the literature..$^{5,20,21}$

Table I Mean pharmacokinetic parameters of gliclazide before and after indinavir administration in rabbits $(n=6)$

\begin{tabular}{|c|c|c|c|}
\hline Pharmacokinetic parameter & Gliclazide & $\begin{array}{l}\text { Indinavir + gliclazide* } \\
\text { (single-dose treatment) }\end{array}$ & $\begin{array}{c}\text { Indinavir + gliclazide* } \\
\text { (multiple-dose treatment) }\end{array}$ \\
\hline$C_{\max }(\mathrm{ng} / \mathrm{mL})$ & $360.68 \pm 2.52$ & $360.86 \pm 1.83$ & $364.62 \pm 2.14$ \\
\hline $\mathrm{T}_{\max }(\mathrm{h})$ & $3.00 \pm 0.00$ & $3.00 \pm 0.00$ & $3.00 \pm 0.00$ \\
\hline $\mathrm{V}_{\mathrm{d}}(\mathrm{L})$ & $17.66 \pm 1.22$ & $17.84 \pm 1.08$ & $17.56 \pm 1.10$ \\
\hline$A \cup C_{0-24}(\mathrm{ng} / \mathrm{mL} / \mathrm{h})$ & $4006.24 \pm 20.55$ & $3969.46 \pm 14.12$ & $3975.08 \pm 21.12$ \\
\hline$A \cup C_{0-\text { inf }}(\mathrm{ng} / \mathrm{mL} / \mathrm{h})$ & $4856.02 \pm 90.60$ & $4789.34 \pm 110.61$ & $4845.16 \pm 113.27$ \\
\hline AUC\%Extrapolation & $17.37 \pm 1.48$ & $20.09 \pm 1.56$ & $20.64 \pm 1.45$ \\
\hline $\operatorname{AUMC}_{0-24}(\mathrm{ng} / \mathrm{mL} / \mathrm{h} * \mathrm{~h})$ & $38945.25 \pm 303.75$ & $37655.96 \pm 213.90$ & $38533.66 \pm 371.77$ \\
\hline $\operatorname{AUMC}_{0 \text {-inf }}(\mathrm{ng} / \mathrm{mL} / \mathrm{h} * \mathrm{~h})$ & $70368.15 \pm 4192.72$ & $700 \mid 4.70 \pm 5529.87$ & $70439.43 \pm 6035.5 \mathrm{I}$ \\
\hline AUMC\%Extrapolation & $43.76 \pm 3.08$ & $46.73 \pm 2.90$ & $47.52 \pm 2.46$ \\
\hline$M R T_{0-24}(h)$ & $9.72 \pm 0.03$ & $9.66 \pm 0.03$ & $9.69 \pm 0.04$ \\
\hline$M R T_{0 \text {-inf }}(h)$ & $14.44 \pm 0.58$ & $14.18 \pm 0.73$ & $|4.4| \pm 0.74$ \\
\hline $\mathrm{CL}(\mathrm{L} / \mathrm{h})$ & $1.14 \pm 0.04$ & $1.13 \pm 0.06$ & $1.13 \pm 0.02$ \\
\hline $\mathrm{K}_{\mathrm{el}}\left(\mathrm{h}^{-1}\right)$ & $0.08 \pm 0.01$ & $0.08 \pm 0.00$ & $0.07 \pm 0.00$ \\
\hline$T_{1 / 2}(h)$ & $8.6 \pm 0.60$ & $8.8 \pm 0.80$ & $8.9 \pm 0.90$ \\
\hline
\end{tabular}

Notes: Data are expressed as mean \pm SEM; *No statistical significance vs gliclazide. 
Table 2 Mean pharmacokinetic parameters of gliclazide before and after ritonavir administration in rabbits $(n=6)$

\begin{tabular}{|c|c|c|c|}
\hline Pharmacokinetic parameter & Gliclazide & $\begin{array}{c}\text { Ritonavir + gliclazide } \\
\text { (single-dose treatment) }\end{array}$ & $\begin{array}{c}\text { Ritonavir + gliclazide } \\
\text { (multiple-dose treatment) }\end{array}$ \\
\hline $\mathrm{C}_{\max }(\mathrm{ng} / \mathrm{mL})$ & $394.71 \pm 1.73$ & $436.91 \pm 2.39 *$ & $446.05 \pm 5.05^{*}$ \\
\hline $\mathrm{T}_{\max }(\mathrm{h})$ & $3.00 \pm 0.00$ & $3.00 \pm 0.00$ & $3.00 \pm 0.00$ \\
\hline $\mathrm{V}_{\mathrm{d}}(\mathrm{L})$ & $17.66 \pm 1.22$ & $17.88 \pm 1.06$ & $17.54 \pm 1.12$ \\
\hline$A \cup C_{0-24}(\mathrm{ng} / \mathrm{mL} / \mathrm{h})$ & $4163.39 \pm 17.34$ & $5102.08 \pm 28.85^{*}$ & $5334.04 \pm 18.44 *$ \\
\hline$A \cup C_{0 \text {-inf }}(\mathrm{ng} / \mathrm{mL} / \mathrm{h})$ & $5032.94 \pm 80.32$ & $6307.27 \pm 54.82 *$ & $6589.44 \pm 25.03 *$ \\
\hline AUC\%Extrapolation & $17.18 \pm 1.21$ & $19.09 \pm 0.50 *$ & $19.05 \pm 0.40 *$ \\
\hline $\operatorname{AUMC}_{0-24}(\mathrm{ng} / \mathrm{mL} / \mathrm{h} * \mathrm{~h})$ & $40023.30 \pm 167.29$ & $49018.03 \pm 436.60^{*}$ & $51758.31 \pm 136.09 *$ \\
\hline $\mathrm{AUMC}_{0 \text {-inf }}(\mathrm{ng} / \mathrm{mL} / \mathrm{h} * \mathrm{~h})$ & $71882.15 \pm 3364.44$ & $94489.99 \pm 2028.89 *$ & $98658.97 \pm 1348.46^{*}$ \\
\hline AUMC\%Extrapolation & $43.72 \pm 2.60$ & $48.03 \pm 0.92 *$ & $47.49 \pm 0.74 *$ \\
\hline $\mathrm{MRT}_{0.24}(\mathrm{~h})$ & $9.61 \pm 0.03$ & $10.66 \pm 0.04 *$ & $1 \mathrm{I} .70 \pm 0.02 *$ \\
\hline$M R T_{0 \text {-inf }}(h)$ & $14.25 \pm 0.45$ & $\mid 6.94 \pm 0.21 *$ & $17.97 \pm 0.16^{*}$ \\
\hline CL (L/h) & $1.14 \pm 0.04$ & $0.929 \pm 0.02 *$ & $0.820 \pm 0.02 *$ \\
\hline $\mathrm{K}_{\mathrm{el}}\left(\mathrm{h}^{-1}\right)$ & $0.08 \pm 0.01$ & $0.06 \pm 0.00 *$ & $0.06 \pm 0.00 *$ \\
\hline$T_{1 / 2}(h)$ & $8.50 \pm 0.50$ & $9.30 \pm 0.20$ & $9.50 \pm 0.10$ \\
\hline
\end{tabular}

Notes: Data are expressed as mean \pm SEM; $* P<0.05$ vs gliclazide.

Indinavir is reported to be metabolized by CYP3A4 and an inhibitor of the cytochrome P450 isoform CYP3A4..$^{30,31}$ As per the FDA label, ${ }^{30}$ co-administration of indinavir and drugs primarily metabolized by CYP3A4 results in increased plasma concentrations of the other drug, which could increase or prolong its therapeutic and adverse effects. Gliclazide is known to be metabolized by hepatic microsomal enzymes CYP2C9 primarily and partly by CYP3A4. ${ }^{5,6,20,21}$ Gliclazide is intensively metabolized into at least 5 metabolites ( $7 \alpha$-hydroxy gliclazide, $6 \beta$-hydroxy gliclazide, $7 \beta$-hydroxy gliclazide, hydroxymethyl gliclazide, and carboxy gliclazide) and only small amounts of unchanged compound are excreted in the urine essentially as oxidized and hydroxylated derivatives, the majority of which undergo glucuroconjugation. 5,27 Therefore, theoretically we may expect that gliclazide concentrations will be increased in the presence of indinavir (by CYP3A4 inhibition). But in contrast to this theoretical expectation, indinavir in combination with gliclazide did not show any significant effect on concentrations or pharmacokinetic parameters, and there was no pharmacokinetic interaction. The absence of pharmacokinetic interactions and changes in the concentrations of gliclazide in the presence of indinavir might be because of the partial contribution of CYP3A4 enzyme in gliclazide metabolism, or because indinavir is not a potent CYP3A4 inhibitor, ${ }^{31}$ or has lower absorption ${ }^{32}$ and protein binding ${ }^{30,32}$ than gliclazide in animal models. Thus this study confirmed that the interaction of indinavir with gliclazide is pharmacodynamic not pharmacokinetic due to the opposing effects of gliclazide and indinavir on glucoseinsulin homeostasis, insulin resistance, and tissue uptake of glucose. These results are consistent with recent clinical studies on diabetes-inducing capacity of indinavir. ${ }^{33,34}$

Ritonavir has been reported to cause new-onset diabetes mellitus, exacerbation of pre-existing diabetes mellitus, and hyperglycemia during postmarketing surveillance in HIVinfected patients. ${ }^{35}$ Our previous pharmacodynamic studies also confirmed these findings and thus, in combination, ritonavir has to decrease the pharmacodynamic activity of gliclazide. But there was a significant rise in serum gliclazide levels and alteration in pharmacokinetic parameters such as $\mathrm{C}_{\max }, \mathrm{AUC}, \mathrm{AUMC}, \mathrm{K}_{\mathrm{el}}$ and $\mathrm{T}_{1 / 2}$ of gliclazide with singleand multiple-dose treatments of ritonavir. The increase in $\mathrm{C}_{\max }$, AUC, and AUMC indicates improved availability of gliclazide in the presence of ritonavir. There might not be an interaction during absorption since oral absorption of ritonavir is not high and absorption rate constant $\left(\mathrm{K}_{\mathrm{a}}\right)$ remained unchanged. Gliclazide and ritonavir are highly protein-bound drugs (gliclazide: $85 \%-99 \%$; ritonavir: $98 \%-99.5 \%$ ) 25,29 and there is every possibility for displacement of gliclazide from the protein binding sites by ritonavir which may lead to increased gliclazide levels. However there was no significant change in $\mathrm{V}_{\mathrm{d}}$ and $\mathrm{T}_{1 / 2}$ of gliclazide in the presence of ritonavir. Hence its protein displacement in the presence of ritonavir was unlikely and not significant. Hence, the rise of gliclazide blood levels in the presence of ritonavir might be through other than improved absorption and altered distribution. The altered $\mathrm{K}_{\mathrm{el}}, \mathrm{T}_{1 / 2}$, and clearance indicates alteration either in the process of metabolism or excretion.

Ritonavir is primarily metabolized by the CYP3A subfamily ${ }^{36,37}$ through $\mathrm{N}$-demethylation, hydroxylation of the isopropyl side chain, and oxidation and cleavage of the 
terminal isopropylthiazole group. ${ }^{38}$ Ritonavir is a well-known potent CYP3A4 inhibitor and is used to enhance the pharmacokinetic and anti-HIV activity profiles of the concomitantly administered PIs, ${ }^{31,35,39}$ and ritonavir is generally considered to have similar CYP3A4-inhibitory potency compared with ketoconazole, a most potent CYP3A4 inhibitor. ${ }^{40}$ Interestingly, some studies reported that tolbutamide-4-hydroxylation was inhibited by CYP2C9 inhibition $^{41}$ and thus ritonavir may also affect CYP2C9 and CYP2C19 activity $^{36,39}$ apart from CYP3A4 inhibition. Further, gliclazide is eliminated through renal $(80 \%)$ and biliary $(20 \%)$ routes $^{25,42}$ and the major elimination pathway of ritonavir is hepatic clearance $(<95 \%){ }^{43}$ Hence the raised serum concentrations of gliclazide in the presence of ritonavir may be due to its reduced metabolism by CYP3A4 inhibition and thus decreased the elimination process as it was supported by a significant decrease in elimination and clearance of gliclazide from the pharmacokinetic parameters.

In animals and in man, among the CYP group of drugmetabolizing enzymes, CYP3A4 is the major phase I drug metabolizing enzyme. It is present in the liver, jejunum, colon, and pancreas. It has broad substrate specificity and is responsible for metabolism of more than $50 \%$ of administered drugs. ${ }^{15}$ However, the liver (300 pmol of total CYPs/mg microsomal protein) and the intestinal epithelia ( 20 pmol of total CYPs/mg microsomal protein) are the predominant sites for $\mathrm{P} 450$-mediated drug elimination, while the other tissues contribute to a much smaller extent to drug elimination. In vivo drug interactions with ritonavir (PIs) are most likely due to mechanism-based inhibition of CYP3A and thus pronounced and sustained elevation of the plasma levels of other PIs as well as pharmacoenhancement of other drugs. This pharmacoenhancement reflects the fact that the currently available HIV PIs are both substrates and inhibitors of CYP3A and thus compete for the same metabolic enzyme at both hepatic and intestinal sites ${ }^{44-46}$ and thus the site of drug interaction of ritonavir with gliclazide was expected to be both at hepatic and intestinal sites. Biochemical and structural studies ${ }^{47}$ have shown that ritonavir is an irreversible type II inhibitor that inactivates CYP3A4 not only by displacing substrates from the active site and tightly binding to the heme iron via the thiazole nitrogen but also by decreasing the protein redox potential and precluding reduction by cytochrome $\mathrm{P} 450$ reductase. Additional possible mechanisms of inhibition by ritonavir which cannot be ruled out include potential to inactivate CYP3A enzymes by the formation of a metabolic intermediate complex, ${ }^{48}$ a competitive ${ }^{49}$ or mixed competitive-noncompetitive CYP3A4 inactivation. ${ }^{50,51}$
The interaction of ritonavir with gliclazide is a pharmacokinetic interaction at a metabolic level (by CYP3A4 inhibition) in normal rabbits while the interaction of indinavir with gliclazide is pharmacodynamic, which needs dose adjustment, and care should be taken when these combinations are prescribed for their clinical benefit in diabetic patients.

\section{Conclusion}

Our study confirmed that the interaction of ritonavir with gliclazide is a pharmacokinetic interaction at a metabolic level by CYP3A4 inhibition in normal rabbits while the interaction of indinavir with gliclazide was pharmacodynamic not pharmacokinetic, which needs dose adjustment, and care should be taken when these combinations are prescribed for diabetes patients. However the present study shows that further studies are warranted to determine the relevance of these interactions in human beings and the exact mechanism of action(s) behind this interaction(s), if any.

\section{Acknowledgments}

The authors are thankful to M/s Aurobindo Pharma Ltd, Hyderabad and M/s Micro Labs, Bangalore for supplying gift samples of PIs and gliclazide respectively. The authors are grateful to Cytel Management, Pune for kind help and support during the pharmacokinetic analysis.

\section{Disclosure}

K Eswar Kumar designed the research and data interpretation; SK Mastan designed the research, performed the research, analyzed data, and drafted the manuscript. Both the authors read and approved the final manuscript. The author(s) declare that they have no competing interests.

\section{References}

1. Dube MP. Disorders of glucose metabolism in patients infected with human immunodeficiency virus. Clin Infect Dis. 2000;31: 1467-1475

2. Samaras K. Prevalence and pathogenesis of diabetes mellitus in HIV-1 infection treated with combined antiretroviral therapy. J Acquir Immune Defic Syndr. 2009;50(5):499-505.

3. Carr A, Samaras K, Thorisdottir A, Kaufmann GR, Chisholm DJ, Cooper DA. Diagnosis, prediction, and natural course of HIV-1 proteaseinhibitor-associated lipodystrophy, hyperlipidaemia, and diabetes mellitus: a cohort study. Lancet. 1999;353:2093-2099.

4. Zimmet P, Alberti KGMM, Shaw J. Global and societal implications of the diabetes epidemic. Nature. 2001;141:782-787.

5. Satyanarayana S, Kumar EK. Influence of nicorandil on the pharmacodynamics and pharmacokinetics of gliclazide in rats and rabbits. Mol Cell Biochem. 2006;291:101-105.

6. Mastan SK, Chaitanya G, Reddy KR, Kumar KE. An appraisal to the special sulphonylurea: gliclazide. Pharmacologyonline. 2009;1: 254-269. 
7. Schernthaner G. Gliclazide modified release: a critical review of pharmacodynamic, metabolic and vasoprotective effects. Metabolism. 2003;52:29-34.

8. Mastan SK, Kumar KE. Effect of indinavir on the pharmacodynamic activity of gliclazide in rats and rabbits. Int J Integr Biol. 2009;7: $16-21$.

9. Mastan SK, Kumar KE. Influence of ritonavir on the pharmacodynamics of gliclazide in animal models. Diabetologia Croat. 2009;38: 105-113.

10. Mastan SK, Kumar KE. Effect of antiretroviral drugs on the pharmacodynamics of gliclazide with respect to glucose-insulin homeostasis in animal models. J Exp Pharmacol. 2010;2:1-11.

11. Lawrence DR, Bacharach AL, editors. Evaluation of Drug Activities: Pharmacometrics. New York, NY: Academic Press; 1964.

12. Hruz PW. Molecular mechanisms for altered glucose homeostasis in HIV infection. Am J Infect Dis. 2006;2:187-192.

13. Gupta RC, Atul BV. Drug metabolism studies in animal models. Ind $J$ Pharmacol. 2000;32:S62-S66.

14. Lin JH. Species similarities and differences in pharmacokinetics. Drug Metab Dispos. 1995;23:1008-1021.

15. Zhang Y, Benet LZ. The gut as a barrier to drug absorption: combined role of cytochrome P450 3A and P-glycoprotein. Clin Pharmacokinet. 2001;40:159-168.

16. Chiba M, Nishime JA, Neway W, Lin Y, Lin JH. Comparative in vitro metabolism of indinavir in primates - a unique stereoselective hydroxylation in monkey. Xenobiotica. 2000;30(2):117-129.

17. Nakamura T, Okada K, Nagata K, Yamazoe Y. Intestinal cytochrome P450 and response to rifampicin in rabbits. Jpn J Pharmacol. 2000; $82: 232-239$.

18. Jasiñska M, Owczarek J, Orszulak-Michalak D. Influence of simvastatin at high dose and nifedipine on hemodynamic parameters in rabbits. Pharmacological Reports. 2006;58:48-59.

19. Fang HM, Xu JM, Mei Q, et al. Involvement of cytochrome P450 3A4 and P-glycoprotein in first-pass intestinal extraction of omeprazole in rabbits. Acta Pharmacol Sin. 2009;30:1566-1572.

20. Satyanarayana S, Kumar KE, Rajasekhar J, Thomas L, Rajanna S, Rajanna B. Influence of aqueous extract of fenugreek-seed powder on the pharmacodynamics and pharmacokinetics of gliclazide in rats and rabbits. Therapy. 2007;4:457-463.

21. Kumar KE, Ramesh A, Satyanarayana S. Pharmacodynamic and pharmacokinetic drug interaction of gliclazide and lacidipine in animal models. Ind J Pharm Educ Res. 2008;42:277-282.

22. Pichard L, Gillet G, Fabre I, et al. Identification of the rabbit and human cytochromes P-450 IIIA as the major enzymes involved in the N-demethylation of diltiazem. Drug Metab Dispos. 1990;18: 711-719.

23. Sinko PJ, Kunta JR, Usansky HH, Perry BA. Differentiation of gut and hepatic first pass metabolism and secretion of saquinavir in ported rabbits. J Pharmacol Exp Ther. 2004;310:359-366.

24. Yeung PK, Mosher SJ, Pollak PT. Pharmacokinetics and metabolism of diltiazem in rabbits after a single intravenous or single oral administration. Eur J Drug Metab Pharmacokinet. 1991;16:69-74.

25. Campbell DB, Lavielle R, Nathan C. The mode of action on clinical pharmacology of gliclazide a review. Diabetes Res Clin Pract. 1991;14: S21-S36.

26. Wajchenberg BL, Santomano ATMG, Porrelli RN. Effect of sulfonylurea (gliclazide) treatment on insulin sensitivity and glucose mediated, glucose disposal in patients with non-insulin dependent diabetes mellitus (NIDDM). Diabetes Res Clin Pract. 1993;20:147-154.

27. Product monograph. ${ }^{\text {PrDIAMICRON }}{ }^{\circledR}$ Gliclazide $80 \mathrm{mg}$ tablets. Hypoglycemic sulfonylurea Oral hypoglycemic agent. SERVIER CANADA Inc. [Date of Revision: 2009 Jan 15. Pages 1-27]. http:// webprod.hc-sc.gc.ca/dpd-bdpp/item-iteme.do?pm-mp=00007471

28. Rollins DE, Klaassen CD. Biliary excretion of drugs in man. Clin Pharmacokinet. 1979;4:368-379.
29. Davis TME, Daly F, Walsh JP, et al. Pharmacokinetics and pharmacodynamics of gliclazide in caucasians and Australian aborigines with type 2 diabetes. Br J Clin Pharmacol. 2000;49:223-230.

30. US Food and Drug Administration [home page on the Internet]. FDA approved drug products: CRIXIVAN ${ }^{\circledR}$ (Indinavir sulfate) Capsules Label; [issued 2010 April 26; cited 2010 Oct 28]. http://www. accessdata.fda.gov/drugsatfda_docs/label/2010/020685s071lbl.pdf

31. Koudriakova T, Iatsimirskaia E, Utkin I, et al. Metabolism of the human immunodeficiency virus protease inhibitors indinavir and ritonavir by human intestinal microsomes and expressed cytochrome p4503a4/3a5: mechanism-based inactivation of cytochrome P4503A by ritonavir. Drug Metab Disp. 1998;26:552-561.

32. Lin JH, Chiba M, Balani SK, et al. Species differences in the pharmacokinetics and metabolism of indinavir, a potent human immunodeficiency virus protease inhibitor. Drug Metab Dispos. 1996; 24:1111-1120.

33. Noor MA, Lo JC, Mulligan K, et al. Metabolic effects of indinavir in healthy HIV-seronegative men. AIDS. 2001;15:F11-F18.

34. Noor MA, Seneviratne T, Aweeka FT, et al. Indinavir acutely inhibits insulin-stimulated glucose disposal in humans:a randomized, placebocontrolled study. AIDS. 2002;16(5):F1-F8.

35. US Food and Drug Administration [home page on the Internet]. FDA approved drug products: NORVIR ${ }^{\circledR}$ (Ritonavir) Tablets Label; [issued 2010 Apr 27; cited 2010 Oct 28]. http://www.accessdata.fda.gov/ drugsatfda_docs/label/2010/020659s050,022417s001 lbl.pdf

36. Kumar GN, Rodrigues AD, Buko AM, Denissen JF. Cytochrome P450-mediated metabolism of the HIV-1 protease inhibitor ritonavir (ABT-538) in human liver microsomes. J Pharmacol Exp Ther. 1996; 277:423-431.

37. Chiba M, Hensleigh M, Nishime JA, Balani SK, Lin JH. Role of cytochrome P450 3A4 in human metabolism of MK-639, a potent human immunodeficiency virus protease inhibitor. Drug Metab Dispos.1996;24:307-314

38. Koudriakova T, Iatsimirskaia E, Utkin I, et al. Metabolism of the human immunodeficiency virus protease inhibitors indinavir and ritonavir by human intestinal microsomes and expressed cytochrome P4503A4/3A5: mechanism-based inactivation of cytochrome P4503A by ritonavir. Drug Metab Dispos. 1998;26:552-561.

39. Hsu A, Granneman GR, Bertz RJ. Ritonavir: clinical pharmacokinetics and interactions with other anti-HIV agents. Clin Pharmacokinet. 1998; 35:275-291.

40. Von Moltke LL, Greenblatt DJ, Grassi JM, et al. Protease inhibitors as inhibitors of human cytochromes P450: high risk associated with ritonavir. J Clin Pharmacol. 1998;38:106-111.

41. Eagling VA, Back DJ, Barry MG. Differential inhibition of cytochrome P450 isoforms by the protease inhibitors, ritonavir, saquinavir and indinavir. Br J Clin Pharmacol. 1997;44:190-194.

42. Oida T, Yoshida K, Kagemoto A, Sekine Y, Higashijima T. The metabolism of gliclazide in man. Xenobiotica. 1985;15:87-96.

43. Izzedine H, Launay-Vacher V, Deray G. Pharmacokinetics of ritonavir and nevirapine in peritoneal dialysis. Nephrol Dial Transplant. 2001; 16:643.

44. Singh R, Chang SY, Taylor LCE. In vitro metabolism of a potent HIVprotease inhibitor (141W94) using rat, monkey and human liver S9. Rapid Commun Mass Spectrom. 1996;10:1019-1026.

45. Eagling VA, Wiltshire H, Whitcombe IWA, Back DJ. CYP3A4-mediated hepatic metabolism of the HIV-1 protease inhibitor saquinavir in vitro. Xenobiotica. 2002;32:1-17.

46. Kumar GN, Jayanti V, Lee RD, Whittern DN, Uchic J, Thomas S, et al. In vitro metabolism of the HIV-1 protease inhibitor ABT-378: species comparison and metabolite identification. Drug Metab Dispos. 1999; 27:86-91.

47. Sevrioukovaa IF, Poulosa TL. Structure and mechanism of the complex between cytochrome P4503A4 and ritonavir. Proc Natl Acad Sci U S A. 2010;107:18422-18427. 
48. Lin JH, Chiba M, Chen IW, et al. Time- and dose-dependent pharmacokinetics of L-754,394, an HIV protease inhibitor, in rats, dogs and monkeys. J Pharmacol Exp Ther. 1995;274:264-269.

49. Iribarne C, Berthou F, Carlhant D, et al. Inhibition of methadone and buprenorphine N-dealkylations by three HIV-1 protease inhibitors. Drug Metab Dispos. 1998;26:257-260.

50. Eagling VA, Back DJ, Barry MG. Differential inhibition of cytochrome P450 isoforms by the protease inhibitors, ritonavir, saquinavir, and indinavir. Br J Clin Pharmacol. 1997;44:190-194.
51. Zalma A, von Moltke LL, Granda BW, Harmatz JS, Shader RI, Greenblatt DJ. In vitro metabolism of trazodone by CYP3A: inhibition by ketoconazole and human immunodeficiency viral protease inhibitors. Biol Psychiatry. 2000;47:655-661.

\section{Publish your work in this journal}

Research and Reports in Endocrine Disorders is an international, peerreviewed, open access journal publishing original research, reports, reviews and commentaries on all areas of endocrinology, endocrine disorders and therapeutic interventions. The manuscript management system is completely online and includes a very quick and fair peer-review system. Visit http://www.dovepress.com/testimonials.php to read real quotes from published authors. 